\title{
O Sistema de AVALIATIVIDADE E OS RECURSOS PARA gradação em Língua Portuguesa: Questões TERMINOLÓGICAS E DE INSTANCIAÇÃO*
}

(Appraisal system and graduation resources in Brazilian Portuguese: terminological and instantiation issues)

Orlando VIAN JR

$(U F R N)$

\author{
"As palavras também têm a sua hierarquia, \\ o seu protocolo, os seus títulos de nobreza, \\ os seus estigmas de plebeu". \\ José Saramago \\ As intermitências da morte, p. 196
}

ABSTRACT: This paper aims to discuss, from Halliday's systemic functional grammar perspective $(1985,1994,2004)$, the problems related to the translation of the term appraisal into Portuguese, as a way of discussing the lexico-grammatical realizations of evaluative stances in texts in Brazilian Portuguese. We will focus on Graduation (Martin and White, 2005; Martin and Rose, 2003), a resource used by text producers to take stances towards what they express and we will also refer to the Bakbtinian notion of dialogism.

KEY-WORDS: appraisal; evaluation; graduation; dialogism; instantiation.

RESUMO: Este artigo pretende, a partir da perspectiva da gramática sistêmico-funcional (Halliday, 1985, 1994, 2004), discutir, em um primeiro momento, a questão terminológica em relaşão ao Sistema de Avaliatividade (Martin and White, 2005; Martin and Rose, 2003) para que, em seguida, encaminhemos a discussão sobre como as instâncias avaliativas são realizadas no texto em português brasileiro. Nosso foco

\footnotetext{
* Agradeço à Leila Barbara pela leitura da versão preliminar deste texto e ao Rodrigo Esteves de Lima-Lopes pela leitura cuidadosa e pelas valiosas sugestões de forma e conteúdo. Também a Carolina Ventura, Mauro Sobhie e Rodrigo Esteves Lima-Lopes pelas discussões na tradução de alguns termos. Além dos instigantes e significativos comentários dos dois pareceristas, a quem agradeço imensamente. As falhas e inconsistências remanescentes, advirto, são de minha inteira responsabilidade.
} 
será principalmente nos recursos para Gradação, e a avaliação negativa utilizada pelo produtor textual para posicionar-se perante o que expressa e, para tanto, recorremos também à noção bakhtiniana de dialogismo.

PALAVRAS-CHAVE: avaliatividade; avaliação; gradação; dialogismo; instanciação.

\section{As atitudes na linguagem}

A maneira como o produtor de um texto oral ou escrito se posiciona em relação ao seu leitor ou a seu interlocutor e a forma como julga o mundo concebido no texto que produz traz à tona diferentes tipos de avaliação. Tais avaliações evidenciam, em termos léxico-gramaticais, os tipos de atitudes negociadas no texto, bem como a força dos sentimentos em relação ao objeto de avaliação.

Diversos são os recursos disponíveis na língua ao produtor de textos para posicionar-se em relação àquilo que expressa e, dessa forma, emitir avaliações sobre pessoas, objetos, entidades e todos os demais aspectos das relações sociais que negociamos em nosso dia-a-dia e que são passíveis de avaliação em suas variadas escolhas. Isso significa que, ao interagirmos, através de textos, sinalizamos para o nosso interlocutor nossas atitudes em relação ao que expressamos. Este, por sua vez, apreende (ou não) o papel a si atribuído para assimilar (ou não) as avaliações nas atitudes emitidas; não se trata de um universo textual, em nível léxico-gramatical, mas vai além disso: um universo extra-textual, em nível semântico-discursivo.

A preocupação com esse universo de possibilidades de avaliação em níveis extra-textuais tem levado pesquisadores à tentativa de compreensão dos mecanismos disponíveis na linguagem a partir de diferentes perspectivas teóricas e metodológicas. Prova disso é que os estudos sobre a avaliação na linguagem remontam ao final da década de 1970 e início da década de 1980, principalmente a partir dos trabalhos de Labov (1972, 1982, 1984, 1997) sobre avaliação e intensidade em narrativas. Sob outras perspectivas teóricas, podemos citar, dentre outros, os trabalhos de Hoey $(1983,2001)$ e também de Biber (2000). Pela perspectiva sistêmico-funcional, diversos são os estudos em relação à avaliação na linguagem; apenas a título de ilustração, cito o trabalho de Eggins e Slade (1997), ao estudarem a avaliação na conversa cotidiana e os trabalhos de Hunston (2000) e Hunston e 
Thompson (2000), além dos trabalhos de Martin (2000, 2002, 2003, 2004) e colaboradores, que serão focados neste artigo (Martin e Rose, 2003; Martin e White, 2005).

Ao abordarmos o papel da avaliação na linguagem, duas premissas tornam-se necessárias: primeiramente, é preciso que adotemos uma perspectiva dialógica para se analisar o sistema lingüístico e as possibilidades nele disponíveis para avaliação para que, em um segundo momento, analisemos, especificamente, os mecanismos disponíveis em Língua Portuguesa para as instanciações dos recursos de Gradação na linguagem.

Paralelamente a tais questões, encaminhamos o início de uma discussão sobre a questão da tradução de alguns termos do sistema de Avaliatividade para o português.

\section{Avaliatividade e avaliação}

Talvez o primeiro aspecto a ser discutido, antes enveredarmos pelas questões de dialogismo e de instanciação propriamente ditas, diga respeito à utilização dos termos relacionados ao Sistema de Avaliatividade e sua aplicação em língua portuguesa.

O fato de se utilizar aqui avaliatividade, em vez de apreciação ou valoração, ou simplesmente avaliação deve-se primeiramente ao fato de se evitar inadequados posicionamentos teóricos, além da confusão terminológica, devida, em parte, à rapidez com que os conceitos foram recebidos no Brasil e, como diversos estudos proliferam em centros de pesquisa pelo país, algumas traduções optaram por apreciação, outras por valoração.

Tal fato é mais do que corriqueiro quando se iniciam aplicações de uma teoria produzida em língua estrangeira que é adaptada para o português. O mesmo ocorreu, por exemplo, no final da década de 1990, com o uso da variável de registro Tenor, em inglês, e sua tradução para o português. A tradução usada para Tenor em Santos (1996) é Teor, assim como para Neves (1997: 75); na tradução do texto de Wells (1998), utiliza-se Tom; Ramos (1997) usa o termo Participantes e Vian Jr (1997: 17) sinaliza, em nota de rodapé, que utiliza o termo Relações "pelo fato de esta variável tratar não só dos participantes do discurso, mas também das relações entre estes e os papéis sendo desempenhados por eles como produtores dos textos". 
Recentemente, parece ter se firmado o termo Relações, constante, inclusive, da lista de termos sistêmico-funcionais em português ${ }^{1}$. Como se vê, à medida que a teoria vai sendo utilizada, os termos vão sendo depurados conforme circulam na comunidade discursiva, até que se chegue ao senso comum e a um item que abarque todo o potencial de significado e de aplicação no idioma.

Nos casos dos termos apreciação ou valoração, há vários motivos para recusá-los. No caso de apreciação, por ser o melhor correspondente a appreciation, um dos três subsistemas de Atitude. Quanto à valoração, tem, primariamente, o sentido de 'atribuir valor a algo', o que reduz significativamente o escopo envolvido na avaliação, uma vez que, juntamente ao valor, agregam-se crenças, emoções, afeto, relações sociais e tantos outros aspectos; e ainda pelo fato de, no subsistema de apreciação, haver o termo inglês valuation, que, em determinados casos, também poderia ser traduzido por valoração.

A opção pela palavra appraisal ${ }^{2}$, em inglês, em vez de evaluation ou assessment, reside exatamente no fato de diferenciar o sistema de outros estudos sobre avaliação, como os de Labov, por exemplo. E avaliatividade, em português, distingue-se ainda do termo valoração usado na análise de discurso de linha francesa, em Maingueneau, por exemplo.

Embora o termo valoração tenha sido incorporado à lista de termos traduzidos para o português como correspondente a appraisal, é provável que tal uso tenha ocorrido pelo fato de o sistema como um todo e todos os subsistemas e categorias envolvidos ainda não estarem sendo muito testados em língua portuguesa e de os pesquisadores não estarem familiarizados com tantas variáveis.

\footnotetext{
1 Há um grupo de discussão de gramática sistêmico-funcional em língua portuguesa, da qual participam pesquisadores de vários centros de pesquisa do país. Para filiação ao grupo, enviar mensagem para gsfemportugues-subscribe@yahoogrupos.com.br. Para a lista de termos sistêmico-funcionais traduzidos para o português, acesse: http://www2.lael.pucsp.br/ tony/sistemica/, em "Termos".

2 Conforme Jim Martin, em comunicação pessoal com o autor no 35th International Systemic Functional Conference, Odense, Dinamarca, e no IV Simpósio Internacional de Gêneros Textuais, Tubarão, Santa Catarina.
} 
O sentido do appraisal system, como se detalhará no item 5, vai muito além de valoração, por isso a sugestão do termo Sistema de Avaliatividade, uma vez que estamos considerando um potencial de significados avaliativos disponíveis no sistema lingüístico e que envolvem, portanto, questões relacionadas à filogênese e à ontogênese para que o nível logogenético se desenvolva em termos de funcionamento lingüístico.

Suponhamos que o fato de tratar avaliatividade e avaliação como sendo o mesmo fenômeno tenha dado origem ao problema da tradução dos termos appraisal e evaluation e seus correspondentes em língua portuguesa. Antes de se pensar em optar por um termo ou outro, é necessário que se estabeleça a diferença entre ambos, em língua inglesa, para que não caiamos em novas falácias.

Vejamos: se considerarmos a escala ${ }^{3}$ de instanciação (Halliday e Mathiessen, 1999; Halliday, 2004) e observá-la pela perspectiva macro dos potenciais de significados disponíveis, teremos, conforme propõem Martin e White (2005: 163), em um pólo a língua como SISTEMA, e, no pólo oposto, as situações ou contextos em que esses significados são realizados individualmente, a língua como TEXTO.

Podemos reduzir o escopo e considerarmos apenas o nível do texto para compreensão da avaliatividade e dos mecanismos lingüísticos para a realização léxico-gramatical dos potenciais de significados disponíveis para realizarmos as avaliações em nosso cotidiano.

Ao pensarmos na relação entre língua e texto em termos da escala de instanciação, temos que a avaliação é apenas a instanciação das opções avaliativas de que a língua dispõe como potencial de significados presentes no texto, ao passo que avaliatividade está relacionada a todo o potencial que a língua oferece para realizarmos significados avaliativos, ou seja, para expressarmos pontos de vista positivos ou negativos, para graduarmos a força ou o foco do que expressamos e para negociarmos a inter-subjetividade e assim por diante.

Pensando nas escalas e posicionando paralelamente a escala da língua e do texto, temos a seguinte correlação:

3 Estou utilizando 'escala de instanciação' como correspondente a 'cline of instantiation'. 


\begin{tabular}{rll}
\multicolumn{1}{r|}{ LÍNGUA } & TEXTO \\
Sistema & Avaliatividade \\
Registro & Seleção \\
Tipo de texto & Posicionamento \\
Instância & Avaliação \\
Leitura & Reação
\end{tabular}

Figura 1: Escala de instanciação: do Sistema para a leitura e da Avaliatividade para a reação

Ao nos referirmos aos mecanismos de projeção (Halliday, 2004: 603613), temos a avaliação realizada de forma modal, estritamente relacionada à metafunção interpessoal e projetada pela modalidade, pela polaridade ou pelo comentário e, para essa ocorrência, Halliday usa o termo assessment. No texto, utilizado como modelo para análise, apresentado em forma de quadro nas páginas 608 a 612 (Halliday, 2004), estabelece-se a relação, para o mesmo texto, entre os tipos de modal assessment e o os tipos de appraisal. Reitero, com isso, a inapropriação do termo apreciação ou valoração, reafirmando o uso de avaliatividade para nos referirmos ao sistema de significados potenciais avaliativos disponíveis para uso.

Como este texto dará enfoque aos recursos para Gradação, sinalizo que o uso do termo também sofreu alterações: no modelo de 2003, Martin e Rose utilizam como as três opções básicas de avaliatividade: Atitude, Amplificação (Amplification) e Fonte (Source) (pp. 24-25), ao passo que no modelo de 2005, Martin e White utilizam Atitude, Gradação (Graduation) e Engajamento (Engagement) (pp. 37-38), revelando o aspecto dos avanços no interior do sistema e as conseqüentes mudanças terminológicas.

Indicadas essas questões, vejamos a relação entre o dialogismo e avaliatividade e, em seguida, aspectos de instanciação no português do Brasil. 


\section{Dialogismo e avaliação}

Para que compreendamos como os significados são realizados do ponto de vista lingüístico, é necessário que partamos do pressuposto de que toda interação verbal é dialógica, porque em toda e qualquer produção verbal cotidiana, seja oral ou escrita, revela-se a assunção de um leitor ou ouvinte: interagimos em função do, para e com o outro. O princípio dialógico de Bakhtin acentua exatamente a natureza contextual da interação, bem como o aspecto sociocultural dos contextos em que as interações são realizadas. O dialogismo, assim, torna-se o ponto de partida para que se encaminhe a discussão sobre a relação entre dialogia e avaliação.

É importante lembrar que, ao discutirem os recursos lingüísticos de que o produtor textual utiliza-se para se posicionar em relação aos valores que expressa em seus textos, Martin e White (2005: 92) informam que a abordagem que utilizam é influenciada pelo conceito bakhtiniano de dialogismo.

Para que se entenda essa inter-relação é importante que se compreenda a relevância do conceito de dialogismo, que permeia toda a obra de Bakhtin e para quem o conceito é o princípio constitutivo da linguagem, pois toda a vida da linguagem é impregnada de relações dialógicas e, conseqüentemente, na nossa relação com o outro está o centro de toda interação verbal: é no exterior, no meio social que está o centro organizador.

Bakhtin (1953/1992: 62) considera que "o signo e a situação social em que se insere estão indissoluvelmente ligados. O signo não pode ser separado da situação social sem ver alterada sua natureza semiótica”. Eis aqui, também, uma das premissas da gramática sistêmico-funcional: a indissociabilidade na relação texto-contexto.

A nossa consciência individual é exteriorizada pela linguagem, caracterizando-se, dessa forma, como um evento eminentemente social e ideológico, daí o fato de o dialogismo assumir, na teoria bakhtiniana, uma dupla função, como nos indica Brait (1997: 98), com ênfases por mim adicionadas em negrito:

Por um lado, o dialogismo diz respeito ao permanente diálogo, nem sempre simétrico e harmonioso, existente entre os diferentes discursos que configuram uma comunidade, uma cultura, uma sociedade. É nesse sentido que podemos interpretar o dialogismo como o elemento que instaura a constitutiva natureza interdiscursiva da linguagem. Por outro lado, o dialogis- 
mo diz respeito às relações que se estabelecem entre o eu e o outro nos processos discursivos instaurados historicamente pelos sujeitos, que, por sua vez, instauram-se e são instaurados por esses discursos. $E$ á, dialógico e dialético aproximam-se, ainda que não possam ser confundidos, uma vez que Bakhtin vai falar do eu que se realiza no nós, insistindo não na síntese, mas no caráter polifônico dessa relação exibida pela linguagem.

O que se depreende, portanto, são dois aspectos relevantes.

- O primeiro é a correlação entre dialogismo e interação verbal, a partir da qual se verifica uma interação permanente entre os participantes do diálogo.

- O segundo está na correlação entre dialogismo e intertextualidade; na qual observamos a interdependência entre discurso e contexto e a relação dialética entre ambos.

Já sugeri em texto anterior (Vian Jr., 2002) alguns possíveis diálogos, embora de perspectivas espaciais, sociais e teóricas diferentes, entre Bakhtin e Halliday. Aqui, reforço esse diálogo, pois, para que esse "permanente diálogo" a que se refere Brait ao discutir a teoria bakhtiniana se realize léxico-gramaticalmente, serão necessários mecanismos lingüísticos que reflitam as relações interpessoais entre os interactantes, que são definidas pelas variáveis de registro, ou seja, o campo, as relações e o modo do discurso determinam como a linguagem será realizada léxico-gramaticalmente nos textos produzidos em dado contexto.

Em termos sistêmico-funcionais, também requer que se enfatize a importância do contexto, uma vez que as teorias de Firth e, posteriormente, as de Halliday tomam como ponto de partida a antropologia de Malinowski. Essa perspectiva estabelece uma relação dialética entre linguagem e contexto, que é considerado tanto no nível cultural (gênero), quanto no nível situacional (registro). É no nível do contexto de situação que operam as três variáveis mencionadas acima (campo, relações, modo) e que realizam, no nível léxico-gramatical, as escolhas dos usuários.

Assim, ao considerarmos o dialogismo bakhtiniano, preceituado, em seu trabalho, frise-se, em relação à literatura, e vislumbrá-lo a partir de uma perspectiva sistêmico-funcional, é preciso que se discuta, ainda, a noção de INSTANCIAÇÃO, pois é este conceito que nos fornece a chave para a 
relação entre SISTEMA e TEXTO: o sistema lingüístico é instanciado em forma de texto. Independentemente do tipo de texto ${ }^{4}$ que se produza, do mais corriqueiro bom-dia a uma tese científica, ou dos valores inerentes a tais textos, qualquer um deles será uma instanciação de um sistema mais amplo.

O bom-dia, a forma mais trivial de se cumprimentar alguém pela manhã, por exemplo, não terá existência se não como tal, ou seja, como texto instanciado naquele contexto. Tome-se, a título de ilustração, o bomdia utilizado pelo irreverente e inconformado Adrian Conauer, vivido por Robin Williams, no filme Bom dia, Vietnã, contrastando o aspecto da guerra iminente e a saudação de um bom-dia em meio a tal cenário. Ou ainda, para ficar no terreno cinematográfico, o filme Boa noite e boa sorte, bordão usado pelo âncora de TV Edward R. Morow para encerrar seu programa de rádio nos anos 1950 em meio à perseguição comunista de McCarthy: Morow deseja o boa noite e o boa sorte, indicando a incerteza do que aconteceria de um dia para o outro, ou seja, ambos os cumprimentos são impregnados de sentidos avaliativos, retirados do contexto do cumprimento diário e inseridos em um novo contexto, assumindo, por conseqüência, novos significados.

O que se quer advogar aqui é que o texto não possui nenhum posicionamento semiótico a não ser em referência ao sistema da língua a que pertence, ou seja, estão imbricados no texto tanto um sistema lingüístico quanto um sistema social.

A relação entre linguagem e contexto e as possibilidades de avaliações que podem ser feitas pelos usuários nos contextos em que interagem faz emergir o Sistema de Avaliatividade como um sistema de recursos interpessoais à disposição do produtor de textos para que se posicione em relação ao que expressa. E aqui a palavra SISTEMA é de suma importância, não se tratando de uma teoria, mas um conjunto, um sistema de opções em nível semântico discursivo à disposição dos usuários que, no nível léxico-gramatical, será instanciado em um texto pelos mecanismos lingüísticos de avaliação dos quais a língua dispõe. Estamos falando, portanto, de

4 Enfatizamos aqui que a noção de texto preceituada por Halliday inclui qualquer produção oral ou escrita. 
atitudes, ou seja, a posição que assumimos perante algo ao avaliarmos o mundo que nos rodeia, mesmo que, em muitos casos, façamos avaliações em determinadas situações em que expressamos atitudes que possam parecer, a nós, como corriqueiras ou inofensivas, mas que podem magoar, ofender, ferir nosso interlocutor.

Muitas vezes, usamos itens lexicais, inclusive substantivos, que, em sua acepção cotidiana, são desprovidos de qualquer avaliação, utilizados pura e simplesmente para nomeação de algo, mas que, inserido em determinado contexto de situação e dadas as relações entre os participantes, assumem características ofensivas ou preconceituosas a partir da relação dialógica entre os participantes.

Tomemos um outro exemplo cotidiano, dessa vez ligado ao esporte, do comentado caso ocorrido em São Paulo, em 2005, durante uma partida da Copa Libertadores da América de Futebol entre o time brasileiro São Paulo e o time argentino Quilmes, em que o jogador argentino Leandro Desábato foi acusado de racismo por chamar o jogador brasileiro de macaco, o que levou o argentino a ser preso em São Paulo, sendo indiciado ainda no estádio, o que virou notícia nacional e internacional.

Em tese, o item lexical macaco é utilizado em sua acepção cotidiana para nomeação de um símio, mas, no contexto de situação em que a relação entre os participantes é a de adversários em uma partida de futebol, acrescida da sugerida rivalidade entre brasileiros e argentinos, assumiu proporções altamente avaliativas, virando, inclusive, caso de polícia. Acresçase o fato de o jogador, vítima de preconceito, independentemente de qualquer avaliação ou julgamento, atender pela alcunha de Grafite, o que por si só, faz referência a um racismo velado, mas que, pare ele, supostamente, não soa como tal, ao passo que macaco, vindo de onde e de quem veio, assumiu outras proporções.

Esses exemplos apontam para a relevância de se considerar o contexto quando se trata de escolhas lingüísticas e das possibilidades de avaliação disponíveis na língua, por isso é necessário que se entenda a relação entre SISTEMA e TEXTO e, para tanto, é necessário também recorrer à noção de INSTANCIAÇÃO, 


\section{Instanciação}

A noção de instanciação é de extrema importância para que se compreenda a relação entre avaliatividade (no nível do sistema) e avaliação (no nível do texto), isto é, a instanciação é a manifestação do sistema lingüístico no texto, o que deve, da mesma forma, ser interpretado como um processo dialético, dado ao fato de que a instanciação se manifesta, constrói e reconstrói os potenciais de significado de determinada cultura.

O que se verifica, dessa forma, é a visão ampla de linguagem tanto como sistema de escolhas disponível aos usuários como quanto texto, a materialização lingüística desse sistema, bem como a relação entre o contexto de cultura e o contexto de situação, como ilustra a Figura 2 a seguir, com base no sugerido por Halliday e Mathiessen (1999: 8), indicando que a linguagem REALIZA o contexto e o texto INSTANCIA o sistema:

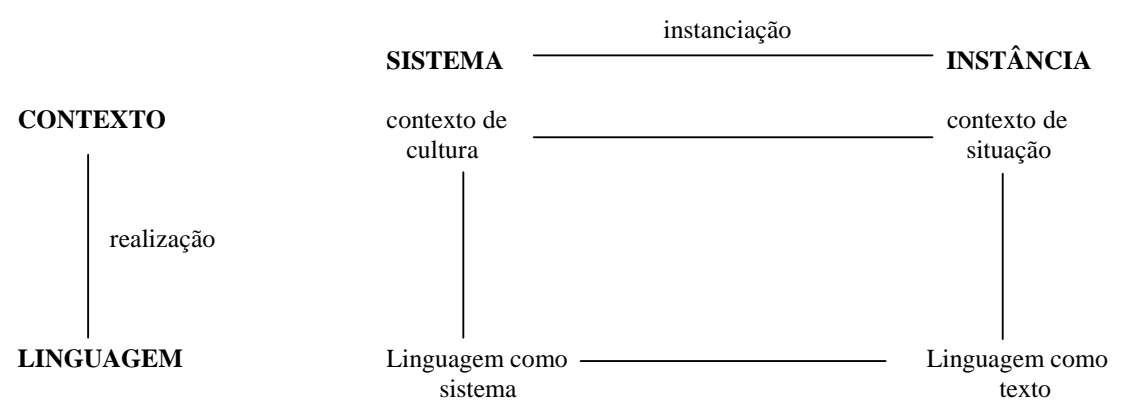

Figura 2: As relações contexto/linguagem, sistema/instância

A figura acima faz com que emirja o que talvez seja o primeiro problema que enfrentamos ao tratarmos da questão dos dois termos em inglês (appraisallevaluation) e sua tradução para o português a partir de uma perspectiva sistêmico-funcional e que está associado a uma questão primordial na relação entre as duas perspectivas pelas quais podemos vislumbrar a linguagem: como SISTEMA e como TEXTO.

A inter-relação sistema-texto pode ser considerada como uma das primeiras dicotomias a ser enfrentada quando nos imbuímos da tentativa de 
explicar como a língua se organiza e, mais que isso, de que modo essa organização está à disposição do ser humano em sua utilização da linguagem no cotidiano. Outra questão a se levantar é a de que talvez estejamos pensando nas duas perspectivas simultaneamente ou em sobreposição, quando, na verdade, estamos tratando de coisas distintas, conforme ilustrado na Figura 1, no item 2.

Halliday (2004: 26-27) metaforiza a relação sistema-texto a partir da relação entre tempo (weather) e clima (climate), que não representam diferentes fenômenos, mas sim o mesmo fenômeno visto de perspectivas diferentes. Em suas palavras, traduzidas livremente por mim: "O tempo é o texto: é o que acontece ao nosso redor o tempo todo, causando impacto, e às vezes, distúrbios em nosso cotidiano. O clima é o sistema, o potencial que subjaz a esses efeitos variáveis".

Glosando a relação clima-tempo estabelecida por Halliday, ofereço aqui um exemplo lhano relacionado à nossa cultura, mas talvez bastante ilustrativo $^{5}$ com o intuito de facilitar a compreensão da relação entre texto e sistema, pois essa relação pode também ser metaforizada por meio do uso do exemplo de uma padaria: há em sua cozinha todo um potencial de pães a serem produzidos, mas lá, na cozinha, reduzem-se apenas à farinha, ou seja, a farinha é todo o potencial de significado que, ao ser manuseado pelos profissionais, transformar-se-á em bolos, pães, brioches, croissants, biscoitos, roscas, pães de queijo, e toda a gama de espécies que podem ser produzidas, de acordo com o contexto de situação daquela padaria.

Logo, essas diferentes espécies de pães são 'textos' instanciados a partir da farinha: a farinha é o sistema, o pão é o texto. A influência do contexto, ainda, vai definir a que gênero o pão-texto pertence, pois, para a mesma ocorrência temos, em diferentes contextos de situação, diferentes tipos de pão, inclusive com nomes distintos em contextos variados.

\section{O Sistema de Avaliatividade}

Ao considerarmos as formas como ocorrem os mecanismos de avaliação do ponto de vista de sua realização léxico-gramatical, temos uma vasta

5 Credito esse exemplo a Mauro Sobhie, de quem tomei emprestada a metáfora. 
gama de escolhas disponíveis no sistema lingüístico. Podemos, por exemplo, ser mais ou menos intensos, pouco ou muito enfáticos, mais ou menos distantes de nossos interlocutores, muito ou pouco formais. Isso equivale a dizer que a linguagem oferece mecanismos diversos para que atribuamos diferentes avaliações aos mais diferentes aspectos de nossas atitudes em nosso cotidiano.

Mesmo considerando a pletora de opções disponíveis na língua das quais podemos fazer uso ao avaliarmos algo, é possível categorizarmos os recursos léxico-gramaticais utilizados nas avaliações.

Para a categorização das ocorrências desse sistema de avaliação, Martin e colaboradores estabeleceram o Sistema de Avaliatividade, consubstanciado principalmente em Martin e White (2005), mas apresentado em outros autores anteriormente, como no próprio Martin (2000, 2002, 2003) e também em Eggins e Slade (1997) e em White (2004a; 2004b), que nos permite analisar, a partir da perspectiva sistêmico-funcional de linguagem, os recursos utilizados, sinalizando, inclusive, para mudanças terminológicas, como já apontado.

Segundo os trabalhos difundidos por pesquisadores ligados à Escola de Sydney, são três os principais tipos de atitudes: expressamos sentimentos e emoções, julgamentos de caráter e avaliações, que podem ser, portanto, categorizados em três tipos de recursos:

\footnotetext{
Afeto recursos utilizados para expressar emoção

Julgamento recursos utilizados para julgar o caráter

Apreciação recursos utilizados para atribuir valor às coisas
}

Paralelamente a estes três recursos, incluem-se, simultaneamente à Atitude, a Gradação e o Engajamento. Ou seja, ao fazermos uma avaliação, também selecionamos o quanto queremos amplificá-la, isto é, se pretendemos aumentar ou diminuir o grau de nossa avaliação, assim como indicamos a fonte de nossa avaliação. Pode-se assim dizer que as atitudes que expressamos distribuem-se por três campos: afeto, julgamento e apreciação, além de, ao externarlizarmos verbalmente nossas atitudes, optamos por graduá-las e o fazemos em relação ao nosso envolvimento com nossos interlocutores e também em relação ao que está sob avaliação. Estas opções, portanto, podem ser resumidas da seguinte maneira: 


\begin{tabular}{|l|l|}
\hline Atitude & Afeto \\
\cline { 2 - 2 } & Julgamento \\
\cline { 2 - 2 } & Apreciação \\
\hline Gradação \\
\hline Engajamento \\
\hline
\end{tabular}

Figura 3: Recursos de avaliatividade

Em relação ao termo Engajamento utilizado na figura acima, estou utilizando como tradução para Engagement; poderia também ser traduzido por Envolvimento, mas o faço pelo fato de, no nível semântico-discursivo, Martin e White (2005) apontarem três possibilidades de recursos para a transmissão de significados interpesoais: Envolvimento (Involvement), Negociação (Negotiation) e Avaliatividade (Appraisal), ou seja, é mais uma maneira de se evitar novas confusões terminológicas.

As atitudes, a partir da perspectiva do Sistema da Avaliatividade, podem ainda ser vistas como um sistema da semântica discursiva, que se realiza léxico-gramaticalmente através de diferentes estruturas gramaticais.

Ao expressamos nossas atitudes, podemos vislumbrá-las como sentimentos institucionalizados (Martin e White, 2005: 45), sendo que o julgamento refere-se ao universo das propostas sobre o comportamento e a apreciação ao universo das proposições sobre o valor das coisas. O afeto, dessa forma, é o centro das atitudes que expressamos. Ontogeneticamente falando, os recursos lingüísticos para a realização da avaliação são apre(e)ndidos nos primeiros estágios do desenvolvimento lingüístico. Assim, o mecanismo da inter-relação entre afeto, julgamento e apreciação pode ser visualizado na seguinte figura, traduzida de Martin e White (2005: 45):

Ética/moralidade (regras \& regulamentos).

Sentimentos institucionalizados como propostas

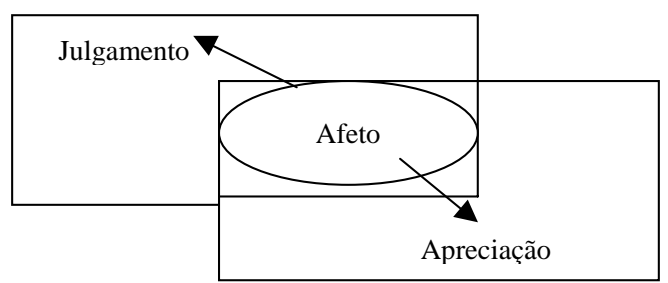

Sentimentos institucionalizados como proposições de estética/valor (critério e avaliação

Figura 4: Julgamento e apreciação como afeto institucionalizado 
$\mathrm{Na}$ teoria sistêmico-funcional, a linguagem é concebida com um sistema semiótico em três estratos: um de significados, um de fraseados e outro de letras/sons. É relevante, neste ponto, estabelecer a relação entre os estratos da linguagem para os níveis de realização lingüística. Temos, primeiramente, em um nível micro, o estrato grafo-fonológico (letras/sons). Em um segundo plano, temos o nível da oração, que é realizada pela léxico-gramática (fraseados) e, por fim, em um terceiro nível, o semânticodiscursivo (significados), localizado em um nível de abstração que está além da oração. A relação entre os três estratos, conforme preceitua a teoria sistêmico-funcional de Halliday, organiza-se da seguinte forma:

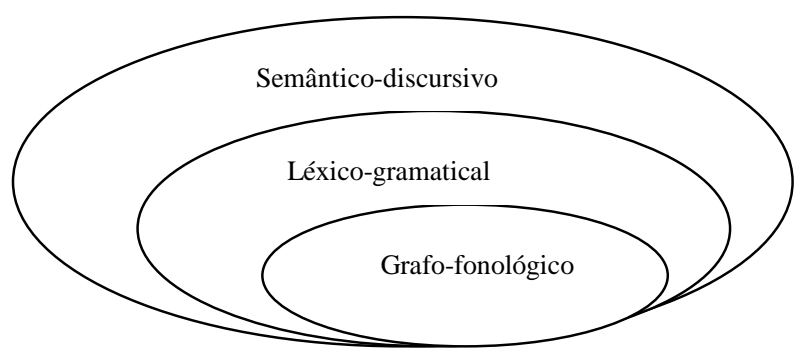

Figura 5: Estratos da linguagem

O Sistema de Avaliatividade, a partir das ilustrações apresentadas, localiza-se no estrato da semântica do discurso e é realizado, em termos lexicais e gramaticais, no estrato da léxico-gramática, oralmente ou escrito, de acordo com a interação que se desenvolve, pelo estrato grafo-fonológico.

Ao selecionar o léxico avaliativo quando julgamos algo, partimos de sistemas semânticos, que são realizados léxico-gramaticalmente de forma a reforçarmos, ampliarmos ou minorarmos, reduzirmos, aquilo que avaliamos. Pode-se dizer, assim, que o Sistema de Avaliatividade caracteriza-se como um sistema interpessoal no nível da semântica do discurso que está articulado, simultaneamente, a outros dois sistemas, Negociação e Envolvimento e, em um nível superior em abstração, está relacionado à variável de registro Relações. Poderíamos, assim, esquematizar as relações entre os elementos do contexto de situação (registro, representada pela variável Relações), a semântica discursivo e a léxico-gramática: 


\begin{tabular}{|l|l|l|}
\hline \multicolumn{1}{|c|}{ REGISTRO } & \multicolumn{1}{|c|}{$\begin{array}{l}\text { SEMÂNTICA } \\
\text { DISCURSIVA }\end{array}$} & LÉXICO-GRAMÁTICA \\
\hline Relações & $\begin{array}{l}\text { Negociação } \\
\text { Avaliatividade } \\
\text { Envolvimento }\end{array}$ & Léxico avaliativo \\
& \\
\hline
\end{tabular}

Quadro 1: A relação contexto/registro, semântica discursiva e léxico-gramática

Reduzindo-se o escopo ao campo central do quadro acima e restringindo-nos apenas aos recursos de avaliatividade (em negrito e sombreado), como uma das áreas da semântica do discurso, chegamos, finalmente, ao Sistema de Avaliatividade. Ao retomarmos e ampliarmos o modelo da Figura 3, representando-o de outro modo, veremos que os três tipos de recursos à nossa disposição para indicarmos as realizações léxico-gramaticais em subsistemas podem ser também representados, com base no sistema mais amplo de significados disponíveis, da seguinte maneira:

\begin{tabular}{|l|l|l|}
\hline \multicolumn{3}{|c|}{ AVALIATIVIDADE } \\
\hline \multicolumn{1}{|c|}{ Envolvimento } & \multicolumn{1}{|c|}{ Atitude } & \multicolumn{1}{c|}{ Gradação } \\
\hline Monoglóssico & Afeto & Força \\
Heteroglóssico & Julgamento & Foco \\
& Apreciação & \\
\hline
\end{tabular}

Quadro 2: Os recursos de avaliatividade

O que se observa na proposta de Martin e White (2005) é que os autores pretendem desenvolver um sistema semântico-discursivo para a avaliatividade, o que sugere uma gama de realizações em diferentes estruturas léxico-gramaticais. Tais realizações, a partir da nomenclatura sugerida por Halliday (1994), realizar-se-á através da modificação de participantes, processos e adjuntos, em diferentes instâncias, podendo configurar-se no texto como qualidades, através de epítetos, atributos e circunstâncias, através de diferentes processos, mas principalmente comportamentais e mentais, ou como comentários, através de adjuntos modais. Ou seja, trata-se de um sistema na interface entre semântica do discurso e léxico-gramática, da realização dos significados no texto através dos recursos disponíveis na semântica do discurso. 
A proposta aqui, portanto, é discutir alguns tópicos relacionados ao uso da gradação em português brasileiro e, pelo fato de a maioria dos recursos no Sistema de Avaliatividade sugeridos por Martin e White (2005) serem aplicáveis ao idioma, propomo-nos a discutir alguns casos típicos que caracterizam a tipologia do idioma, através do uso de recursos não disponíveis ou diferenciados da língua inglesa, como é o caso da ordem dos elementos no grupo nominal para aumento e diminuição da força do que é expresso pelo usuário.

Reforço: trata-se simplesmente do levantamento de alguns aspectos tipológicos de nosso idioma, que, como tal, está sujeito a críticas e alterações. Pretendo apenas trazer à baila a relevância que mais estudos sobre o assunto têm para o estudo da tipologia do português brasileiro em termos sistêmico-funcionais. $\mathrm{Na}$ verdade, estou apenas seguindo os passos propostos por Martin e White e tentando aplicá-los ao estudo do idioma, uma vez que se trata de uma área muita ampla, pois está ligada à semântica do discurso e, todo aquele envolvido na análise sobre como ocorre a avaliação no discurso deparar-se-á com tais aspectos, como bem sugerem os autores (2005: 46):

Thus our mapping of feeling (for affect, judgement and appreciation) have to be treated at this stage as hypotheses about the orgnization of the relevant meanings - offered as a challenge to those concerned with developing appropriate reasoning, as a reference point for those with alternative clasifications and as a tool for those who need something to manage the analysis of evaluation in discourse.

Acrescemos, ainda, o fato de os autores estarem fazendo tal afirmação em relação ao estudo dos três subsistemas (Afeto, Julgamento, Apreciação) relacionados ao sistema de Atitude, ao passo que aqui são focados especificamente aspectos relacionados à Gradação.

Vejamos, com base nesses conceitos, como tais ocorrências realizam-se em textos produzidos em língua portuguesa, através dos exemplos que serão apresentados no item subseqüente.

\section{Recursos para Gradação no português brasileiro}

Para discutir aspectos do SISTEMA DE AVALIATIVIDADE, bem como os RECURSOS PARA AVALIAÇÃO disponíveis em Língua Portu- 
guesa, dentro do subsistema de Gradação e dos significados disponíveis na língua para enfatizar ou reduzir a força das avaliações, utilizaremos exemplos retirados do livro Mundo Perdido, de Patrícia Melo (2006).

Mundo Perdido compõe-se de 20 capítulos e, para a seleção das ocorrências, optamos por recortes de diferentes capítulos, para que o leitor tenha uma visão panorâmica de como a linguagem avaliativa permeia o texto.

A partir da seleção desses excertos, pretendemos discutir a maneira como a autora seleciona recursos de gradação em seu texto, acentuando a avaliação negativa e trazendo ao leitor o mundo marginal e, embutido nisso, uma sátira social. Nosso objetivo, portanto, está em apontar aspectos semânticos e léxico-gramaticais da variante brasileira da língua portuguesa em relação à Gradação e como esta se realiza léxico-gramaticalmente, tomando-se por base a história narrada por Máiquel, também protagonista de $O$ matador (Melo, 1995), outro livro da mesma autora transformado no filme $O$ homem do ano, e que, na presente narrativa, retorna, depois de 10 anos foragido, com o intuito de encontrar sua filha, Samanta, e matar a segunda esposa, Érica, e o novo marido desta, Marlênio, um pastor evangélico, que fugiram com a filha de seu primeiro casamento e com seu dinheiro.

Antes de tudo é preciso sinalizar que a avaliação já está presente no título do livro, pois, ao retratar um mundo perdido, já se tem a pista de que vamos mergulhar em um mundo sem solução, um mundo de crimes, irregularidades e ilegalidade. Ressaltamos também que o item lexical 'foragido' é recorrente em todo o livro, de forma a marcar a condição em que se encontra o protagonista. A narrativa inicia-se com essa indicação, como a primeira oração da narrativa:

Sou foragido. (p. 9, grifo meu)

E, da mesma forma, após diversas recorrências para que fique bem claro o seu posicionamento social e discursivo, encerra-se a narrativa, no último parágrafo:

Não quis nem saber. Sou foragido. Virei as costas e entrei no carro. (p. 205, grifo meu) 
As incursões do personagem ao mundo marginal são várias, uma vez que o périplo para que encontre a filha inicia-se em São Paulo, cruzando o interior do Estado em direção ao Mato Grosso do Sul e Mato Grosso, passando por várias cidades desses Estados, indo até a Bolívia e depois a Belém do Pará e encerra-se em Manaus, cenários nos quais são apresentados ao leitor os mais diversos tipos de crime: roubos de cargas e caminhões, narcotráfico, comércio ilegal de armas, exploração ilegal de madeira, exploração de menores e diversos outros. Pelo fato de o mundo ser visto e narrado pela perspectiva de Máiquel, um marginal matador, tem-se uma visão marcadamente negativa do país e de seu povo. Dessa forma, podemos verificar os mecanismos disponíveis em língua portuguesa e como estes funcionam em relação ao léxico avaliativo de cunho negativo.

Assim como em língua inglesa, os mecanismos em língua portuguesa para intensificação das avaliações são bastante amplos. Observemos o seguinte trecho de Melo (2006: 9-10):

Vai amanhã bem cedo. Era o problema da Eunice, muito mandona. No início, duvidava de tudo o que eu dizia. Uma vez, chegou a arrancar o telefone da minha mão, para checar com a enfermeira a idade da tia Rosa. Expliquei milhões de vezes que eu era o único sobrevivente da família, depois que meu primo Robinson morreu, a tia Rosa ficou muito triste.

Os itens em negrito trazem diferentes tipos de avaliação, com modificações em vários aspectos, relacionados às qualidades, aos processos e outras escolhas léxico-gramaticais impregnadas de avaliação quando relacionadas ao contexto de situação em que se desenvolve a narrativa de Patrícia Melo, ocorrendo os mais diversos tipos de avaliação disponíveis no Sistema de Avaliatividade. Apresentarei e discutirei aqui, como sinalizei, apenas alguns representativos de aspectos tipológicos do português brasileiro em relação à gradação.

Primeiramente, é relevante mencionar a questão da ordem do epíteto no grupo nominal: por ser primariamente um modificador do nome, ocorre, com maior freqüência, posposto ao nome que qualifica:

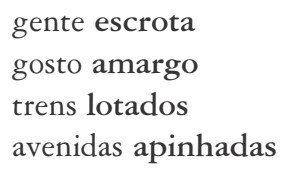


No entanto, para exprimir a qualidade que distingue ou que individualiza algo, pode ocorrer anteposto ao substantivo:

\author{
bom negócio \\ bom agenciador \\ grande Máiquel
}

Quando procedemos a uma avaliação, o foco de nossas atitudes recai em categorias que, vistas pela perspectiva experiencial, não apresentam escalas gradativas, mas operam como forma de reconstruir categorias de gradação em relação ao item que é avaliado. Como nos exemplos abaixo:

Brasileiro é assim, escroto mesmo.

Sou comprista mesmo.

Só xingando mesmo.

Esse mecanismo, portanto, é denominado Foco. Tem por função, ainda, acentuar ou amenizar determinada perspectiva.

Além do mecanismo de Foco, os recursos de Gradação podem também ser realizados pelo mecanismo de Força da avaliação, e a língua portuguesa dispõe de diversos recursos para que possamos graduar e reforçar a nossa avaliação sobre algo, dentre eles, os mecanismos de repetição e a utilização de prefixos e sufixos que aumentam ou diminuem a força das avaliações.

A repetição de um mesmo item lexical é um recurso freqüentemente utilizado para intensificarmos a força de algo. Nos exemplos a seguir, as personagens desejam reforçar os aspectos negativos da cidade de São Paulo e da cidade de Campo Grande e, para isso, utilizam o modificador repetidas vezes:

Mais cachorro. Mais barulho. Mais sujeira também.

Muito feia esta terra, muita gente, muita pobreza, muito dinheiro, muito prédio, muita puta, muito lixo, muito trânsito...

... lá tem muita puta, muita droga e muito árabe.

Dentre os diversos prefixos gregos e latinos presentes no português, muitos são utilizados com a função de intensificar a avaliação de acordo com o item que antepõem: 
... tem um shopping superlegal.

Já estava ultraligado no repórter...

O mesmo mecanismo pode acontecer pelo emprego de sufixos, através dos quais é possível intensificar a característica de um nome adicionando-se o sufixo aumentativo:

Corpão, toda malhada.

Eu tinha perdido um tempão

cada carrão

mulherão na TV.

Como a narrativa de Mundo Perdido é pautada pelas aventuras de Máiquel, um matador de aluguel, e seu contato com o submundo, vale ressaltar a constante referência a itens lexicais de linguagem chula ou tabuística utilizada no decorrer da narrativa, principalmente na forma de nominalizações, quando este se refere a outros personagens e ao contexto.

De bostas, como nossos políticos.

Desses merdas, que só pensam em roubar

Ou, ainda, como já mostrado anteriormente, através do uso de sufixos aumentativos que adicionam um aspecto ainda mais avaliativo a um item chulo já impregnado de avaliação:

você está fodidaço

E mesmo a repetição de itens de um mesmo campo semântico:

E são tantos os ladrões, os corruptos, os filhos-da-puta, os assassinos, escroques, falsários

São corruptos, ladrões, cheiradores de pó.

Por outro lado, a força também pode ser reduzida por meio do uso de palavras de aspecto avaliativo negativo, que, por sua vez, caracterizam as condições sub-humanas de vida em locais periféricos, o que ocorre, por exemplo, com palavras do campo semântico de casa, mas com um aspecto negativo, como ocorre com o emprego de palavras como muquifo, buraco, barraco; ou palavras relacionadas ao crime, como tramóias, esquema, sacana- 
gem; além de outras ocorrências que demonstram o preconceito de Máiquel:

Mas eu não mato corno. Nem trabalho para veado.

... não fique à noite zanzando por aí com preto. Porque primeiro ele vêm atrás dos pretos.

A redução da força avaliativa pode também ocorrer através do acréscimo, a determinados itens lexicais, do sufixo diminutivo, o que pode reduzir a força de algo de diferentes maneiras:

(a) depreciativa

ele disse, o cara-de-pau, com um sorrisinho

fazendo um monte de gracinhas

esses caras fazendo piadinhas

aquela branquela

(b) afetiva, carinhosa

Branquinhos os dentes da Divani.

começar uma vida nova numa cidadezinha

Se eu estou assim, meio tristinha, é só comprar uma blusinha nova, um brinquinho

As coisas estavam iguaizinhas.

O sufixo diminutivo tem um valor avaliativo bastante significativo, agregando-se não só a epítetos e classificadores, mas também a nomes e modificadores.

Outro aspecto característico do português é que os sufixos flexionamse em gênero e número, traço tipológico do idioma:

masculino singular: novinhO

masculino plural: branquinhOS

feminino singular: blusinhA

feminino plural: iguaizinhAS

A alternância entre a intensificação e a redução da força revela aspectos grotescos, como no exemplo abaixo, em que fica patente o aspecto esdrúxulo do que está sendo avaliado.

o narigão, a boquinha, a testona, o dentinho 
Outra forma de avaliação no texto de Melo ocorre através da seleção de processos verbais, nos quais a autora tenta realçar aspectos negativos, utilizando processos marcadamente avaliativos:

ela não sair cacarejando...

Aí desembestou a falar, foi o resto do trecho tagarelando.

A cabeça emperrou

meu cérebro pifa.

a multidão urrava

Ainda em relação aos processos, um recurso comum utilizado pela autora é a recorrência ao léxico atitudinal, realizado muitas vezes pelo uso de processos relacionais, tanto atributivos como identificativos em relação às características negativas dos aspectos avaliados, como ilustram os seguintes exemplos:

\begin{tabular}{|l|l|l|}
\hline Nossa justiça & É & lerda. \\
Cristo & é & fopa deles. \\
{$[\mathrm{Eu}]$} & sou & foragido. \\
[Os ricos] & são & corruptos, ladrões, cheiradores de pó. \\
[e] Nossos pobres & são & igualmente escrotos. \\
[Os ricos] & continuam & uns escrotos. \\
\hline \multicolumn{1}{|c|}{ Portador } & Processo: & Atributivo/Identificador \\
& Relacional & \\
\hline
\end{tabular}

Quadro 3: Processos relacionais

Além dos processos, ocorre também a metáfora como recurso de avaliação, tendo em vista que talvez seja um dos mecanismos mais utilizados no cotidiano, pois é a forma que o produtor de textos encontra de fazer comparações e de usar termos no lugar de conceitos que pretende criar. Observemos as seguintes ocorrências:

E faz a gente viajar que nem tartaruga

Tinha língua, o Josias

Josias tomou rebite, para ficar acordado.

Percebe-se, a partir desses exemplos, que o usuário, na falta da palavra que expresse a atitude que quer transmitir, metaforiza o sentido, como na 
comparação com a tartaruga para dizer que viajam devagar. No exemplo seguinte, ao dizer que o Josias tinha língua, Máiquel usa 'ter língua' para dizer que a personagem não é muda como ele pensava, pois não tinha falado até então, metaforizando a capacidade da fala. A terceira ocorrência, tomar rebite, denotativamente uma haste de metal cilíndrica e parte do cotidiano de caminhoneiros, é utilizada conotativamente para se referir às drogas ingeridas para que se mantenham acordados e cumpram os prazos de entregas de cargas.

Finalmente, ocorrem casos de intensificação em que modificadores são utilizados para se reforçar algum aspecto negativo por meio do emprego de outros modificadores ou intercalando-os ao epíteto, como nos exemplos abaixo:

Muito. Muito mesmo.

... ficou mais feio ainda.

Apareceu ainda mais gente.

... você está encrencado, bastante encrencado.

Ao observarmos as possibilidades de ocorrência dos recursos léxicogramaticais para a realização dos significados avaliativos apresentados até aqui, podemos estabelecer, com base em Martin e Rose (2003: 48), mecanismos de força e de foco, que podem ser acentuados ou amenizados. Dentre os mecanismos de força, foram apresentados ocorrências por meio do uso de intensificadores, léxico atitudinal, metáforas e linguagem chula, sendo que esses recursos podem ser aumentados ou diminuídos, de acordo com a intenção avaliativa do interactante.

Os recursos para Gradação, no entanto, são mais complexos e apresentam diversos desdobramentos possíveis que, devido ao escopo deste trabalho, não foram apresentados aqui. O capítulo 3 de Martin e White (2005) apresenta um sistema em rede para os recursos de Gradação.

O Sistema de Avaliatividade proposto por Martin e White (2005) em relação aos recursos para Gradação mostra-nos que as categorias sugeridas pelos autores podem ser aplicadas à língua portuguesa da mesma forma como são utilizadas na língua inglesa, como originalmente proposto. As diferenças, no entanto, estarão nas formas como as ocorrências serão instanciadas de acordo com os gêneros e com o registro da cultura local, determinando a realização léxico-gramatical das ocorrências. Emergirão, daí, 
ocorrências específicas do português brasileiro e, pela relação dialética entre texto e contexto, teremos itens típicos do contexto, como os aspectos relacionados ao crime nos exemplos apresentados.

A opção por apresentar exemplos de avaliação negativa se deu a partir da leitura do texto de Melo e de toda a gama de ocorrências presentes no texto, que revelam aspectos culturais da sociedade brasileira pela perspectiva da autora. Além disso, a abordagem sistêmico-funcional desenvolvida por Halliday tem como ponto de partida o contexto, que pode ser interpretado através do discurso, realizado léxico-gramaticalmente. Além, é claro, de aspectos tipológicos típicos da língua portuguesa, como o caso do diminutivo e outros aspectos que se refletem na linguagem que, numa análise mais densa, fazem emergir aspectos da cultura do jeitinho, do levar vantagem sobre o outro, da negação da cidadania, do conformismo, e outros tantos aspectos da cultura brasileira que Resende (1992) classifica como "doenças culturais que fragilizam a sociedade brasileira", que, embora não tenham sido demonstrados neste texto, podem ser desenvolvidos em estudos futuros.

Essas "doenças", portanto, são realizadas lingüisticamente pelo léxico presente nos diferentes textos e mostram a relação texto-contexto, como pôde ser observado através dos exemplos retirados de Melo (2006), e que abrem perspectiva para um trabalho mais amplo, que mostre as relações entre as doenças culturais apontadas por Resende (1992) e sua realização léxico-gramatical em textos.

Os exemplos apresentados ilustram ainda as diversas possibilidades de Gradação em língua portuguesa. Reforçamos o fato de que os itens aqui apresentados pretendem ser apenas ilustrativos e não intencionam, de forma alguma, esgotar o assunto, mas apenas apresentá-los para que se tenha uma dimensão dos aspectos tanto práticos quanto teóricos sobre a utilização dos recursos no Sistema de Avaliatividade, assim como as implicações teóricas desse sistema e que possam ser ampliadas e levadas adiante, sendo aplicada a outros contextos.

Os aspectos aqui apresentados tentaram ilustrar os mecanismos utilizados por Patrícia Melo em sua narrativa de Mundo Perdido, uma sátira, uma crítica social ao Brasil e seu mundo do crime, o que imprime à sua narrativa uma profusão de itens avaliativos que reforçam, a partir das escolhas feitas pela autora, os aspectos negativos da cultura brasileira e do 
povo, tais como a corrupção e o mundo do crime, que emergem a partir das escolhas lingüísticas feitas pela autora e a ênfase no léxico avaliativo marcadamente negativo.

\section{Considerações finais}

Talvez o primeiro aspecto que se depreenda ao revisitar o Sistema de Avaliatividade, conforme proposto por Martin e White (2005), é o quão complexo ele se configura e as mais diversas nuances para a apreensão da avaliação e como ela ocorre na linguagem através de mecanismos lingüísticos, tanto lexicais quanto semânticos e gramaticais. Nossa proposta, aqui, foi o de utilizar o termo avaliatividade para que se possa apreender a noção de SISTEMA em relação à avaliação, realizada no TEXTO.

Argumentamos, ainda, em relação à não-utilização dos termos valoração e apreciação para o sistema como um todo. O termo valoração por estar relacionado, em um primeiro momento, apenas ao ato de atribuir valor, embora, certamente, podem agregar-se a ele outros aspectos, mas trata-se de um sentido restrito que não abarca todo o potencial de significados imbricados no potencial de significados disponível para avaliarmos, uma vez que fatores como afeto, contato social, crenças, representações, valores, elementos culturais e tantos outros interpenetram a avaliatividade.

Pensando na questão polissêmica em relação à profusão de termos relativos ao Sistema de Avaliatividade, teremos diversas palavras consideradas sinônimas do verbo avaliar em português, como por exemplo, agaloar, ajuizar, apreşar, apreciar, aquilatar, avaliar, avaluar, bitolar, calcular, computar, considerar, distinguir, esmar, estimar, medir, orçar, suputar, valorizar. O mesmo ocorrendo para o inglês, em que encontramos palavras do mesmo campo semântico, tais como appraisal, appraisement, appreciation, assessment, calculation, estimate, estimation, evaluation, interpretation, judgement, opinion, rating, reasoning, reckoning, valuation. Tais palavras podem, sim, ser sinônimas de avaliação em determinados contextos, mas absolutamente sem sentido em outro e, aqui, estamos tratando do potencial de significados de avaliação, ou seja, um sistema com um escopo macro e não micro, daí a relação avaliatividade/avaliação, no mesmo nível de relação entre sistema/texto.

Ao considerarmos os aspectos dos potenciais de significados disponíveis no sistema lingüístico ao usuário da língua e que se realizam léxico- 
gramaticalmente nas interações cotidianas em forma de textos, propormos a seguinte figura como forma de estabelecer a relação:

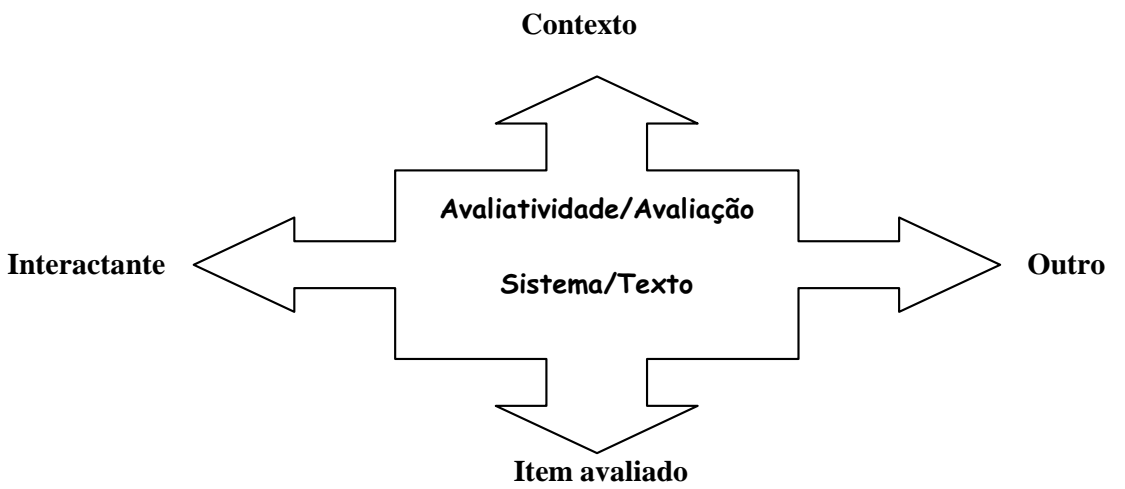

Figura 7: O processamento da avaliação a partir do Sistema de Avaliatividade

A inter-relação entre esses elementos, que coloca o Sistema de Avaliativade em funcionamento, proposta na Figura 7 acima, desenvolve-se da seguinte forma:

(1) Inserido em um contexto sócio-histórico, cultural e institucional, está o Interactante, determinado por suas relações sociais, que emite a avaliação sobre algo ou alguém do mundo que o rodeia.

(2) Ao proceder a qualquer tipo de avaliação, utiliza o Item avaliado recorrendo a um sistema de significados avaliativos em potencial que está à sua disposição e que lhe permite realizar determinadas escolhas em detrimento de outras.

(3) As escolhas realizadas léxico-gramaticalmente a partir das metafunções (experiencial, interpessoal, textual) pelos sistemas (transitividade, modo, modalidade, tema) a elas inerentes, por sua vez, são determinadas pelo Contexto, pelas variáveis de registro, ou seja, o contexto de situação em que o produtor de textos se insere e as escolhas do texto que vai produzir, o modo como vai optar por produzir esses textos e com base nas relações estabelecidas entre o indivíduo e seu universo. 
(4) A avaliação sendo feita, no entanto, só fará sentido se assumida pelo Outro, o interlocutor, e percebida como tal, pressupondo-se que o interlocutor partilhe ou pressuponha os mesmos valores sociais emitidos, assimilando assim a avaliação e assumindo o seu papel, posicionando-se em relação a ela, implicando, além disso, o aspecto eminentemente dialógico do Sistema de Avaliatividade.

A avaliatividade, dessa forma, está relacionada ao sistema e cada uma das escolhas avaliativas feitas pelo usuário, permeadas por outros discursos, por suas crenças, seus julgamentos, suas experiências de mundo, afeto e diversos outros elementos contextuais e individuais serão instanciadas e realizadas no texto léxico-gramaticalmente. Isso significa que uma avaliação pode não ser assumida como tal, dependendo da relação entre os usuários, das diferenças culturais e sociais, pois um item lexical pode assumir um significado avaliativo em um contexto e não em outro.

Daí a necessidade de estabelecermos a correlação entre SISTEMA e TEXTO, para que se compreenda o funcionamento das diferentes instâncias em que a língua funciona, o que reforça ainda mais o caráter contextual da gramática sistêmico-funcional de Halliday, evidenciando que as escolhas que fazemos são dialógicas e ideológicas: fazemos determinadas escolhas em detrimento de outras baseadas em nossas relações sociais, nos papéis sociais que desempenhamos naquele dado contexto e em nossa relação com nossos interlocutores.

Há que se considerar, ainda, o fato de termos abordado neste artigo apenas o recurso da Gradação, tendo apenas sinalizado, do ponto de vista teórico, os recursos de Envolvimento, que compreendem os aspectos monoglóssicos e heteroglóssicos e o recurso da Atitude, que envolve as categorias de Afeto, Julgamento e Apreciação e que merecem ser mais amplamente discutidos.

O foco foi o uso da linguagem avaliativa marcadamente negativa em que o protagonista de Mundo Perdido (Melo, 2006) apresenta suas visões, do lugar social de um foragido da polícia, sobre um Brasil corrupto, ilegal, que infringe leis, normas, regras para que se sobreviva em meio à pletora de irregularidades que o caracteriza, mostrando a relação linguagem-texto-contexto e como a expressão do conteúdo de nossas visões de mundo realizam-se léxico-gramaticalmente através das avaliações que permeiam nossos discursos. 
Em relação às diversas categorias propostas por Martin e White (2005), observa-se que são absolutamente pertinentes ao português brasileiro, devendo-se levar em consideração apenas os aspectos lexicais e determinadas marcas que não existem na língua inglesa, como é o caso da afixação para aumentativo e diminutivo e também da posição dos epítetos e classificadores que, em inglês, possui um estatuto diferente do português. No mais os sistemas e subsistemas são absolutamente correlacionados.

Os conteúdos levantados neste texto pretendem apenas servir como deflagradores de novas e mais amplas discussões sobre os recursos de avaliatividade disponíveis em língua portuguesa, bem como suscitar novas e mais amplas discussões sobre o assunto, as quais, espero, possam ser cada vez mais densas e profícuas e possam abrir veredas para os estudos da gramática funcional sistêmica de Halliday em língua portuguesa.

Recebido em abril de 2007. Aprovado em fevereiro de 2008. E-mail: orlandovianjr@uol.com.br

\section{REFERÊNCIAS BibLIOGRÁFICAS}

Bakhtin, M. 1953. Os gêneros do discurso. In: Estética da criação verbal. São Paulo: Martins Fontes, 1992.

BRAIT, B. 1998. Bakhtin e a natureza constitutivamente dialógica da linguagem. In: Brait, B. (org) Bakbtin, dialogismo e construção de sentido. Campinas: Editora da Unicamp.

Biber, D. et al. 2000. Longman Grammar of Spoken and Written English. London: Longman.

EgGins, S. e Slade, D. 1997. Analysing casual conversation. London: Cassell. Halliday, M.A.K. 1985. An Introduction to Functional Grammar. Londres: Edward Arnold. . 1994. Introduction to Functional Grammar. 2nd. Edition. Londres: Edward Arnold. . 2004. An Introduction to Functional Grammar. $3^{\text {rd }}$. Edition. Revisada por Mathiessen, M.I.M. London: Arnold.

Halliday, M.A.K. e Mathiessen, C.M.I.M. 1999. Construing experience through meaning: a language based approach to cognition. London: Cassell. 
Hoey, M. 1983. On the surface of discourse. London: Unwin. .2001. Textual interaction: an introduction to written discourse analysis. London: Routledge.

Hunston, S. 2000. Evaluation and the planes of discourse status and value in persuasive texts. In: Hunston, S. e G. Thompson (eds). Evaluation in text: authorial stance and the construction of discourse. Oxford: Oxford University Press.

Hunston, S. e Thompson, G. 2000. Evaluation in text: authorial stance and the construction of discourse. Oxford: Oxford University Press.

LABOV, W. 1972. The transformation of experience in narrative syntax. Language in the Inner City. Philadelphia: Pennsylvania University Press. . 1982. Speech actions and reactions in personal narrative. In: D. Tannen (ed) Analysing discourse: text and talk. Washington, D.C. . 1984. Intensity. In: D. Schiffrin (ed). Meaning, form and use in context: linguistics applications. Washington, D.C.: Georgetown University Press.

. 1997. Some further steps in narrative analysis. Journal of Narrative and Life History 7.1-4. 1997: 395-415.

MarTin, J. R. 2000. Beyond Exchange: Appraisal system in English. In: Hunston, S. e Thompson, G. Evaluation in text: authorial stance and the construction of discourse. Oxford: Oxford University Press.

. 2002. Blessed are the peacemakers: reconciliation and evaluation.

In: C. Candlin (ed.) Research and practice in professional discourse. Hong Kong: City University of Hong Kong Press. 187-227. .2003. Instantiating Appraisal: key and stance. Paper at Systemic Functional Linguistics Association Conference, Adelaide. . 2004. Sense and sensibility: texturing evaluation. In J. Foley (ed.) Language Education and Discourse. London: Continuum.

Martin, J. R. e Rose, D. 2003. Working with discourse: meaning beyond the clause. London: Continuum.

MarTin, J.R. e White, P. 2005. The language of evaluation: Appraisal in English. London: Palgrave Macmillan.

Melo, P. 1995. $O$ matador. São Paulo: Companhia das Letras. . 2006. Mundo perdido. São Paulo: Companhia das Letras.

Neves, M.H.M. 1997. A gramática funcional. São Paulo: Martins Fontes.

Ramos, R.C.G. 1997. Proję̧ão de imagens através de escolbas lingü̈sticas: um estudo no contexto empresarial. Tese de doutorado. PUC/SP.

Resende, E. 1992. Cidadania, o remédio para as doenças culturais brasileiras. São Paulo: Summus Editorial. 
Santos, V.B.M.P. 1996. Padrões interpessoais no gênero cartas de negociação. Dissertação de mestrado. PUC/SP.

ViAn JR. O. 1997. Conceito de gênero e análise de textos de vídeos institucionais. Dissertação de mestrado. Pontifícia Universidade Católica de São Paulo. . 2002. Sobre o conceito de gêneros de discurso: diálogos entre Bakhtin e a lingüística sistêmico-funcional. In: Brait, B. Estudos enunciativos no Brasil: história e perspectivas. Campinas: Pontes.

WelLs, G. 1998. Da adivinhação à previsão: discurso progressivo no ensino e na aprendizagem de ciências. In: Coll, C. e Edwards, D. (orgs) Ensino, aprendizagem e discurso em salada de aula - aproximações ao estudo do discurso educacional. Porto Alegre: Artmed.

White, P. 2004a. Valoração: a linguagem da avaliação e da perspectiva. Trad. Débora de Carvalho Figueiredo. In: Coulthard, C. R. C e Figueiredo, D. C. (orgs) Linguagem e discurso: análise crítica do discurso. V.4 número especial: 177-205.

. 2004b. The Language of Attitude, Arguability and Interpersonal positioning. The Appraisal Website: Homepage. Disponível em: http:/ /www.grammatics.com/appraisal/. Acesso em 14.12.06. 